\title{
Entre la juridificación y la profundización de la democracia social: elementos para pensar los conflictos alrededor de los manuales de convivencia en las instituciones educativas y los derechos fundamentales de los estudiantes
}

Between Juridification and Deepening Social Democracy: Key Elements to Discuss the Conflicts Around the Rules of Coexistence within Educational Institutions and the Fundamental Rights of Students Entre a juridificação e o aprofundamento da democracia social: elementos para pensar os conflitos ao redor dos manuais de convivência nas instituições educativas e os direitos fundamentais dos estudantes

\author{
JaVier Orlando Aguirre Román ${ }^{*}$ \\ ANA PATRICIA PABÓN MANTILLA ${ }^{*}$ \\ IVETH PaOla Moreno BernaL ${ }^{\star \star *}$
}

FECHA DE RECEPCIÓN: 28 DE ENERO DE 2019. FECHA DE APROBACIÓN: 4 DE JUNIO DE 2019

Doi: http://dx.doi.org/10.12804/revistas.urosario.edu.co/sociojuridicos/a.7604

Para citar: Aguirre Román, J. O., Pabón Mantilla, A. P., Moreno Bernal, I. P. (2019). Entre la juridificación y la profundización de la democracia social: elementos para pensar los conflictos alrededor de los manuales de convivencia en las instituciones educativas y los derechos fundamentales de los estudiantes. Estudios Socio-jurídicos, 22(1), 391-415. Doi: http://dx.doi.org/10.12804/revistas.urosario.edu.co/sociojuridicos/a.7604

* Doctor y magíster en Filosofía de la Universidad Estatal de Nueva York. Especialista en Docencia Universitaria, abogado y filósofo. Profesor Titular de la Escuela de Filosofía de la Universidad Industrial de Santander (UIS), Bucaramanga, Colombia. Miembro del grupo de investigación Politeia de la UIS. Correo electrónico: jaguirre@uis.edu.co. ORCID: https://orcid. org/0000-0002-3734-227X

** Doctora en Derecho, magíster en Hermenéutica Jurídica y Derecho, especialista en Docencia Universitaria, abogada y filósofa. Profesora Titular de la Facultad de Ciencias Jurídicas y Políticas de la Universidad Autónoma de Bucaramanga (Unab), Bucaramanga, Colombia. Líder del grupo de investigación Teoría del Derecho y Formación Jurídica. Correo electrónico: apabon742@unab.edu.co. ORCID: https://orcid.org/0000-0002-2550-135X

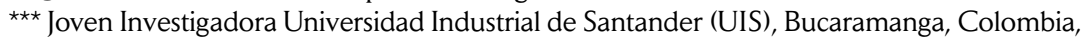
(Convocatoria 2017 de Colciencias). Estudiante de la Maestría en Filosofía de la Universidad Industrial de Santander (UIS) y Filósofa. Miembro del grupo de investigación Politeia de la UIS. Correo electrónico: iveth.moreno@correo.uis.edu.co. ORCID: https://orcid.org/0000-0001-9959-1979. 


\title{
RESUMEN
}

El presente texto tiene como objetivo central abordar el debate acerca de la definición de reglas en los manuales de convivencia y las formas de mediar conflictos entre los distintos actores del sistema escolar en Colombia. El análisis describe las tensiones entre legitimidad y democracia por un lado, y disciplina y autonomía de las instituciones por otro, a partir de dos referentes teóricos, el planteamiento de Habermas sobre la noción de juridificación y el de Bobbio sobre democracia social. La investigación es de tipo teórico; se propone una reflexión desde la hermenéutica crítica de los resultados del análisis documental de las decisiones de la jurisprudencia colombiana sobre manuales de convivencia. La revisión de los referentes filosóficos y el análisis de la forma en que se ha abordado el conflicto en las instituciones escolares permite concluir que, a pesar de que exista una juridificación de la escuela que se visibiliza con la intervención vía tutela contra las instituciones, en muchas ocasiones esto ha sido una respuesta de los distintos actores para frenar la ausencia de democracia social en las instituciones escolares.

Palabras clave: Habermas, Bobbio, manuales de convivencia, instituciones escolares, derechos fundamentales.

\begin{abstract}
The text addresses the debate about the definition of rules of coexistence and the ways of mediating conflicts between the different actors of the school system in Colombia. The analysis describes the tensions between legitimacy and democracy, on the one hand, and the autonomy of the institutions on the other. Our view develops Habermas' perspective on juridification and Bobbio's ideas about social democracy. The theoretical research follows the methodology of critical hermeneutics to present the results of the documentary analysis of the decisions of the Colombian jurisprudence on rules of school coexistence. All of the above allowed us to conclude that although there is indeed a real process of juridification, it has been a response to the weak social democracy that exists within educational institutions.
\end{abstract}

Keywords: Habermas, Bobbio, rules of coexistence, educational institutions, fundamental rights.

\section{RESUMO}

O presente texto tem como objetivo central abordar o debate acerca da definição de regras nos manuais de convivência e as formas de mediar conflitos entre os diferentes atores do sistema escolar na Colômbia. A análise descreve as tensões entre legitimidade e democracia por um lado e disciplina e autonomia das instituições pelo outro, a partir de dois referentes teóricos, a abordagem de Habermas sobre a noção de jurisdição e de Bobbio sobre democracia social. A pesquisa é de tipo teórico, propõe-se uma reflexão desde a hermenêutica crítica dos resultados da análise documental das decisões da jurisprudência colombiana sobre manuais de convivência. A revisão dos referentes filosóficos e a análise da forma em que se tem abordado o conflito nas instituições escolares permitiram concluir que apesar de que exista uma juridificação da escola que se visibiliza com a intervenção via tutela contra as instituições, em muitas ocasiões isto tem sido uma resposta dos distintos atores para frenar a ausência de democracia social nas instituições escolares.

Palavras-chave: Habermas, Bobbio, manuais de convivência, instituições escolares, direitos fundamentais. 


\section{Introducción}

La Constitución Política de Colombia consagra en su artículo 67 que la educación es "un derecho de la persona y un servicio público que tiene una función social" (Congreso de Colombia, 1991, art. 67). También señala que mediante la educación se "formará al colombiano en el respeto a los derechos humanos, a la paz y a la democracia" (Congreso de Colombia, 1991, art. 67). En consonancia con este mandato, desde hace ya varios años, la Federación Colombiana de Trabajadores de la Educación (FECODE) y el Centro de Estudios de Investigaciones Docentes (CEID) han promovido una campaña llamada Escuela, Territorio de Paz. ${ }^{1}$

La necesidad de la campaña y el sentido de la misma presuponen que la realidad de la escuela colombiana ha estado atravesada por la guerra y el conflicto. Así ha sido, de hecho, reconocido desde FECODE: "Si levantamos la consigna de convertir a la escuela en territorio de paz es porque ella ha sido también territorio de guerra, de muchas guerras" (Acuña, 2018, párr. 5).

La primera guerra que se nos viene a la mente es, por supuesto, el largo conflicto armado que ha afectado profundamente la vida de los estudiantes, los profesores y, en general, de todos los agentes del sector educativo en Colombia. ${ }^{2}$ Desde acá, concebir a la escuela como territorio de paz es importante "para reconstruir la memoria histórica de la escuela con relación a la guerra y la violencia, los efectos que ha padecido, cómo ha subsistido, cómo se ha jugado para que en medio de las armas no se agote la pedagogía, ni las posibilidades, ni las esperanzas de una escuela en una Colombia sin guerra y con justicia social" (Fecode $\mathcal{G}$ CEID, 2016, p. 5).

Ahora bien, como se señaló, la consigna Escuela, Territorio de Paz no se refiere solo a una sino a muchas guerras; nos invita entonces a pensar en los demás conflictos que se viven a diario en nuestras instituciones educativas y que requieren ser nombrados, pensados, analizados,

\footnotetext{
Algunas reflexiones sobre el tema fueron consignadas en el número 116 de la revista Educación y Cultura.

2 En el artículo titulado "La victimización de los docentes", publicado en el número 116 de la revista Educación y Cultura, Jorge Ramírez da cuenta del número de maestros asesinados en el contexto del conflicto armado entre los años 1977 y 2016.
} 
discutidos y, en lo posible, resueltos o, al menos, canalizados de forma creativa y pacífica.

En este texto queremos acercarnos a uno de estos conflictos, un conflicto con varias dimensiones, y que está ligado a las reglas de convivencia escolar de las instituciones escolares que generan desacuerdos entre maestros y directivos, por un lado, y los estudiantes y sus familias por otro, reglas que son acusadas de vulnerar los derechos fundamentales de los estudiantes. Estas disposiciones no sólo generan diversos conflictos que atentan contra la paz de las instituciones, sino que cuestionan su papel como formadoras para la garantía de los derechos humanos y la democracia, tal como fue dispuesto por la Constituyente.

En este conflicto, podemos identificar como actores a los estudiantes que enfrentan situaciones de discriminación, exclusión y opresión por parte de las figuras de autoridad de los colegios: profesores y directivas. Es el caso de los estudiantes sancionados por razones de orientación sexual o cuando son "sorprendidos" en manifestaciones de afecto con sus parejas del mismo sexo, o cuando las instituciones fijan reglas que restringen la identidad de género al imponer determinado corte de cabello o limitan el uso de uniformes o accesorios; ${ }^{3}$ situaciones de este tipo reproducen estereotipos y conductas que se observan en distintos niveles sociales y generan situaciones de exclusión y discriminación. Los estudiantes y sus familias han encontrado en la acción de tutela una herramienta para la protección de sus derechos a partir de los desarrollos adelantados en la jurisprudencia de la Corte Constitucional, que ha fijado los límites de la potestad sancionatoria de las instituciones. En este sentido, "la jurisprudencia constitucional es unívoca en afirmar que el ejercicio de la potestad disciplinaria por parte de las autoridades de los establecimientos educativos debe (i) cumplir con los estándares mínimos del derecho sancionador;

3 Para el primer caso se puede citar la Sentencia T-478 de 2015, en donde se analiza la situación de acoso que vivió Sergio David Urrego Reyes luego de que personal de su institución decomisara un celular en el que estaba archivada una foto suya con su pareja dándose un beso, lo que desencadenó un acoso sistemático contra él y su familia, que lo llevó a tomar la decisión de quitarse la vida. Para el segundo caso se puede citar la Sentencia T-562-2013 que analiza la negativa de la institución escolar de permitir a Kim, persona identificada sexualmente como trans, el ingreso a clases por vestir el uniforme femenino y la Sentencia T-565-2013 en donde un joven que se autoreconoce con identidad sexual diversa porta el cabello largo contrario a lo dispuesto por el manual de convivencia. 
y (ii) actuar de forma armónica y coordinada con los propósitos formativos del servicio público educativo, por lo que no puede desligarse de un objetivo pedagógico definido" (Sentencia T-565-2013). ${ }^{4}$

De otra parte, son actores de este conflicto los profesores y las directivas académicas agobiados por las precarias condiciones laborales y materiales que los rodean: salarios ínfimos, un elevado número de estudiantes en sus clases, recursos educativos limitados, infraestructura deficitaria, familias desinteresadas del proceso educativo de sus hijos e hijas, ${ }^{5}$ etc. $Y$ a todo esto se le debe agregar el sentimiento de impotencia generalizada que tienen algunos, pues perciben que el proceso educativo se deslizó de sus manos y ahora depende de una serie de procedimientos impersonales $\mathrm{y}$ fríos mediados por completo por lógicas legales y judiciales. Esto hace que, en muchos casos, las "políticas educativas vulneren su autonomía, sintiéndose por ello desmotivados puesto que su desempeño carece de valoración y reconocimiento" (Granados, 2014, p. 43). Estos docentes y directivas consideran que las decisiones judiciales les restan autoridad y, como ya señalaban desde el 93 "por culpa de los fallos, ahora no hay quien meta en cintura a los alumnos" (Revista Semana, 1993, párr. 1, [en línea]).

Estas críticas no han cesado y quizás uno de los puntos más álgidos del debate se dio en 2016 con ocasión de la revisión sistemática a los manuales de convivencia que ordenó la Corte Constitucional en la Sentencia T-478 de 2015, la cual obligaba a cumplir el mandato constitucional y legal de ajustar los reglamentos escolares a los principios constitucionales. Como se recordará, ciertas voces de la sociedad civil llegaron a indicar que el Sistema Nacional de Convivencia Escolar y Formación para el Ejercicio de los Derechos Humanos, Sexuales y Reproductivos y la Prevención y Mitigación de la Violencia Escolar reproducía e imponía, desde el Estado,

4 Un análisis sobre la naturaleza de los manuales de convivencia y los límites a la potestad de las instituciones escolares en materia disciplinaria puede encontrarse en Aguirre, J., y Pabón, A. (2018). Justicia y derechos en la convivencia escolar. Análisis de la jurisprudencia de la Corte Constitucional colombiana sobre los derechos fundamentales de los estudiantes y los manuales de convivencia de las instituciones educativas. Bucaramanga: Universidad Industrial de Santander.

5 La familia, pese a su rol determinante en el proceso de formación, como lo han mostrado algunos estudios al respecto, "ha cedido la mayor parte de la responsabilidad de la educación de los hijos a la escuela" (Granados, 2014, p. 47). 
una "ideología de género" que iba en contra de los derechos de las familias a orientar la educación sexual de sus hijos (Caracol Radio, 2016).

Paradójicamente, se ha observado que pese a que existe un rechazo generalizado por la intromisión de las normas, reglamentos e intervenciones externas en el proceso educativo, intromisión que ha llevado a una "burocratización de la institucional escolar" producto de una "excesiva normatización que hace que las directivas y los maestros se conviertan en aplicadores de las normas y exigencias administrativas y académicas (...), olvidando su función pedagógica" (Parra, 1994, p. 53, citado por Aristizábal y López, 2014, p. 63), lo cierto es que los maestros y directivos suelen acudir también a la fuerza de las normas, en su caso de reglamentos escolares, como instrumentos para disciplinar a los estudiantes y frenar conductas. Los manuales de convivencia son usados como instrumento para conseguir disciplina, condición que es valorada como necesaria para el proceso de formación por parte de algunos maestros sin que se explore otras posibilidades de acción (Aristizábal \& López, 2014).

En lo que sigue, presentaremos una serie de reflexiones sobre el conflicto brevemente descrito desde la perspectiva de la filosofía política y del derecho contemporáneo, entendiendo que uno de los roles de la filosofía política, tal y como lo señaló Rawls, es

[...] fijar la atención en las cuestiones profundamente disputadas y ver si, pese a las apariencias, puede descubrirse alguna base subyacente de acuerdo filosófico y moral. O si no puede encontrarse dicha base de acuerdo, quizás al menos pueda limitase la divergencia de opinión filosófica y moral que está en la raíz de las diferencias políticas divisivas. (Rawls, 2002, p. 23)

Nos interesa entonces reflexionar desde perspectivas filosóficas que nos permitan pensar propuestas de definición de las reglas legítimas que deberían guiar la convivencia escolar y las formas de resolver las tensiones entre los distintos actores del sistema de convivencia escolar en pro de la educación para la paz y la democracia.

En este sentido presentaremos dos perspectivas aparentemente contradictorias y que, por lo mismo, nos sirven para pensar y discutir el conflicto descrito. La primera de ellas corresponde a la propuesta realizada por Jürgen Habermas en su libro Teoría de la acción comunicativa, II (1992) en 
relación con los peligros del derecho para las sociedades modernas y los procesos de juridización. La segunda de ellas corresponde a la propuesta realizada por Norberto Bobbio en su libro El futuro de la democracia (1986) acerca de la democracia social como la mejor, o tal vez la única, forma de profundizar este tipo de sistema político.

El presente texto constituye una reflexión a partir de los resultados de la investigación Las nociones de democracia que subyacen en la jurisprudencia de la Corte Constitucional colombiana, en la que se estudia el período comprendido entre 1998 y 2015 y cómo se da la protección de los derechos fundamentales de los estudiantes ante las medidas sancionatorias pedagógicas contenidas en los manuales de convivencia en las instituciones escolares. En la investigación se realizó un análisis sistemático de la jurisprudencia de la Corte Constitucional, como fuente documental. Se identificó la jurisprudencia que desde 1998 hasta 2015 abordó situaciones en las que los tutelantes consideraban que los reglamentos escolares vulneraban sus derechos constitucionales fundamentales. La jurisprudencia identificada se organizó en cuatro escenarios jurisprudenciales según los tipos de faltas en que fueron sancionados los actores. Posteriormente, se identificaron las subreglas jurisprudenciales propuestas por la Corte para dar solución a los casos (Pabón \& Aguirre, 2018). En segundo lugar, se propusieron categorías de análisis desde la filosofía política y del derecho contemporáneo, que permitieron la reconstrucción de las distintas nociones de democracia; para dicho análisis se hicieron resúmenes analíticos de las fuentes consultadas. Finalmente, se aplicaron las categorías de análisis de la teoría a las decisiones judiciales con el fin de evaluar los argumentos del juez constitucional y valorar con qué noción de democracia podrían identificarse. Los hallazgos de dicho análisis son retomados en este texto, con la intención ya no de describir los resultados, sino de reflexionar sobre estos desde el enfoque de la hermenéutica crítica.

\section{Habermas y los posibles impactos negativos de la juridificación en la escuela}

El filósofo alemán Jürgen Habermas, en su libro Teoría de la acción comunicativa II (1992), hizo uso de un concepto que resulta de gran impor- 
tancia para la discusión acá presentada: la juridización (Verrechtlichung). ${ }^{6}$ Según Habermas, el proceso de juridización de los espacios de la vida humana estructurados comunicativamente sirve de ejemplo para explicar y comprender la tesis de la colonización interna del mundo de la vida ocurrida en la modernidad. Para Habermas, las patologías de las sociedades occidentales contemporáneas se pueden explicar por la acción de los mecanismos sistémicos que "acaban desplazando las formas de integración social, incluso en aquellos ámbitos en los que la coordinación de la acción en términos de consenso no tiene sustitución alguna; es decir, incluso allí donde lo que está en juego es la reproducción simbólica del mundo de la vida" (Habermas, 1987, pp. 279-280). Los imperativos de los subsistemas económicos y administrativos penetran desde fuera en el mundo de la vida y obligan a que las lógicas propias de este último se asimilen a las lógicas propias de los primeros (Habermas, 1987, p. 502).

La juridización de los espacios de la vida humana estructurados $\mathrm{co}^{-}$ municativamente es un proceso que se desarrolla cuando la integración social es reemplazada por la integración sistémica. Como parte de este proceso ocurre la ampliación de la práctica e intervención del derecho positivo a campos en los que la intervención era mínima o inexistente, los cuales eran anteriormente regulados por consensos culturales y axiológicos (por ejemplo, la educación, la familia, las relaciones amorosas y de amistad, el tiempo libre, etc.).

Ahora bien, como el mismo Habermas lo reconoce, en términos más generales, la juridización puede también describir la tendencia que vemos en las sociedades modernas en las que el derecho escrito, por una parte, extiende su radio de acción y regula asuntos sociales que solían ser regulados de manera informal y, por otra, se subdivide en materias particulares cada vez más delimitadas. Esto último Habermas lo llama adensamiento (Habermas, 1992, p. 504).

6 Habermas reconoce que la autoría del término le pertenece a Otto Kirchheimer, quien lo introdujo para describir cómo los conflictos de clase se habían institucionalizado en términos del derecho salarial y del derecho del trabajo. En este sentido, según Habermas, Kirchheimer pretendía dar cuenta del "acotamiento jurídico de los enfrentamientos sociales y de las luchas políticas" (504 - 505). En relación con el término, también es pertinente anotar que Manuel jiménez Redondo optó por usar para su traducción el término "juridización cuando Verrechtlichung aparece en solitario y "juridificación" cuando aparece acompañado de genitivo objetivo. 
De ahí que de forma muy general se puedan señalar cuatro hornadas de juridización. ${ }^{7}$ En palabras del mismo Habermas:

La primera hornada conduce al Estado burgués, que se desarrolló en Europa Occidental en la época del Absolutismo, en forma de sistema de estados europeos. La segunda hornada conduce al Estado de derecho, que adoptó una forma paradigmática en la monarquía alemana del siglo XIX. La tercera hornada conduce al Estado democrático de derecho, que se difundió en Europa y en Norteamérica como consecuencia de la Revolución Francesa. La que por el momento es la última hornada conduce, finalmente, al Estado social y democrático de derecho, cuya institucionalización en el curso del siglo XX es fruto de las luchas del movimiento obrero europeo, y que, por señalar un caso concreto, ha quedado codificado en el artículo 21 de la Constitución de la República Federal Alemana. (Habermas, 1992, p. 505)

En el contexto de la última hornada, Habermas ejemplifica cómo la juridización ha operado en la colonización del mundo de la vida, a través del derecho de familia y del derecho escolar. Este último es de gran relevancia para nosotros, ya que nos muestra el lado negativo del conflicto descrito en la introducción y nos permite entender las críticas de buena parte de los profesores y las directivas escolares.

Como se señaló anteriormente, la juridización se refiere al uso del derecho positivo como un medio para regular y estructurar los ámbitos de la vida humana informalmente organizados. Se trata entonces de la aplicación de la ley positiva del Estado "a situaciones de acción que están insertas en contextos informales del mundo de la vida" (Habermas, 1992, p. 519). En el caso concreto del "derecho escolar", la juridización ha significado la introducción en los ámbitos escolares de los principios del Estado de derecho, introducción que se materializa, por ejemplo, en la protección jurídica otorgada a estudiantes y padres de familia frente a las medidas pedagógicas, tales como las calificaciones finales, la repetición de los cursos, etc., o frente a los actos de las autoridades escolares

Estas hornadas le sirven a Habermas como evidencia del proceso y como ejemplificación de la intromisión del sistema al mundo de la vida y sus resultados, los cuales generaron transformaciones a nivel social que dieron paso a la creación de nuevas instituciones sociales que velarían en adelante por la preservación de los derechos conseguidos. 
(algunos de ellos operan como medidas disciplinarias) que puedan considerarse atentatorios de los derechos fundamentales de los estudiantes. En el caso alemán, esta implantación "vino motivada por la jurisprudencia y fue emprendida por la burocracia del ministerio de Educación por vía administrativa" (Habermas, 1992, p. 521). Así, según Habermas, los procesos de enseñanza y las medidas escolares obtuvieron una forma jurídica que los hizo accesibles al examen judicial y a las intervenciones burocráticas (Habermas, 1992, p. 521); este proceso se asemeja bastante al de Colombia.

La formalización de las relaciones que se desarrollan en los ámbitos escolares implica para los participantes de estos procesos una objetivización (Versachlichung) y desmundanización de la convivencia escolar, la cual ahora queda regulada formalmente (Habermas, 1992, p. 522). Los sujetos que participan de la relación pedagógica corren el riesgo de quedar reducidos a ser considerados meros sujetos jurídicos que adoptan los unos frente a los otros una actitud objetivante orientada hacia el éxito (Habermas, 192, p. 522). Esta objetivización implica la imposibilidad de situar y comprender las diferencias y los conflictos en el terreno del mundo de la vida en el que surgen, puesto que el derecho se convierte en el único medio para abordarlos.

Como se ve, Habermas presenta una visión crítica de las implicaciones de la aplicación generalizada del derecho en los procesos de formación escolar. Esta aplicación termina generando una serie de perturbaciones funcionales que afectan negativamente los procesos de enseñanza y aprendizaje desarrollados en las instituciones educativas. Podríamos describir estas perturbaciones en los siguientes cinco niveles.

En primer lugar, los sistemas jurídicos y administrativos del Estado son recargados con tareas para las que, en principio, no son competentes, ya que (i) la formación de los agentes jurídicos y burocráticos no suele ser pedagógica, (ii) desconocen el contexto real y detallado en el que surgen los conflictos y (iii) su vinculación con la institución escolar es accidental y pasajera. Para el caso concreto de la situación alemana, Habermas señala que los estudios sociojurídicos sobre la juridificación en el ámbito familiar han evidenciado que los jueces "emiten sus sentencias sobre una deficiente base informativa y que se orientan predominantemente al "bienestar corporal" del niño aun a costa de su bienestar "mental" 
(Habermas, 1992, p. 523). Algo similar puede esperarse de las decisiones judiciales en el campo escolar, en virtud de la participación de agentes que, en principio, no tienen una fuerte vinculación con los procesos que se adelantan en las instituciones educativas. Como corolario evidente de esta sobrecarga sistémica, el campo escolar es regido y orientado por lógicas externas y poco funcionales al mismo.

En segundo lugar, una vez se introduce el derecho como medio en los ámbitos escolares, se combina irremediablemente con otros medios de integración sistémica modernos, a saber, el dinero y el poder administrativo. De esta manera, los conflictos que realmente se resuelven suelen ser aquellos cuyos participantes cuentan con los medios económicos y burocráticos para alcanzar una efectiva representación legal. Es altamente probable que los casos resueltos por la jurisprudencia constitucional colombiana, aquellos que llegan a los medios de comunicación, constituyan una pequeña parte en relación con la gran cantidad de violaciones de derechos, opresiones y discriminaciones sufridas por miles de niños y niñas que, justamente por su precariedad, simplemente no pueden hacer uso de mecanismos legales como la acción de tutela, o también puede suceder que las violaciones y exclusiones más profundas, aquellas relacionadas con la calidad del proceso educativo, simplemente no tengan forma de expresión política al quedar veladas por conflictos como los divulgados por la prensa nacional.

En tercer lugar, la juridificación implica la burocratización de los procesos escolares, los cuales se vuelven rígidos a pesar de que muchos de ellos requieren soluciones inmediatas, flexibles y creativas. Lo cierto es que la juridificación en el campo escolar no se reduce a la protección de los derechos de los estudiantes frente a los manuales de convivencia de las instituciones educativas. Es un fenómeno más amplio que también incluye los formatos que deben diligenciar permanentemente los docentes como parte de su trabajo, los informes de rendición de cuentas acerca de los manejos internos de las relaciones informales con sus estudiantes, la hiperreglamentación de los currículos, el aseguramiento casi judicial de las calificaciones, etc. La juridificación significa entonces que los procesos de enseñanza y aprendizaje se justicializan y burocratizan: "el medio «derecho» colisiona con la forma de la acción pedagógica. La socialización escolar queda descompuesta en un mosaico de actos administrativos 
impugnables" (Habermas, 1992, p. 525). Y, como lo indica Habermas, todo esto genera fenómenos como la despersonalización, la inhibición de las innovaciones, la supresión de la responsabilidad, el inmovilismo educativo, etc. (Habermas, 1992, p. 526).

En cuarto lugar, la intermediación del derecho implica también un cambio lingüístico en la comunicación educativa, la cual ya no se realiza desde los roles y los lenguajes que se han establecido en los procesos de enseñanza y aprendizaje, pues es reemplazada por un lenguaje jurídico que, en principio, no se concibió como aplicable para estos procesos. En este contexto, el riesgo es que ni las directivas ni los profesores de las instituciones escolares van a encontrar los recursos linguísticos para discutir de manera particular con el estudiante los motivos, las afecciones o los porqués de su desarrollo personal, cognitivo o emocional, sino que, sencillamente, se van a acomodar a la aplicación de la norma jurídica como la mejor guía para sus comportamientos.

Finalmente, en quinto lugar y en estrecha conexión con la perturbación anterior, la juridización implica la abstracción de las relaciones pedagógicas que se dan en la escuela. El conocimiento del contexto de los conflictos se desconoce porque se impone desde fuera una mirada objetivizante; mirada en la que las subjetividades propias de los participantes de estas relaciones quedan subyugadas a la norma jurídica abstracta e impersonal. En palabras de Habermas:

La subsunción de la educación bajo el medio «derecho» determina que «los implicados en el proceso pedagógico queden abstractamente incluidos, en tanto que sujetos jurídicos individualizados en un sistema de competencia y rendimiento. La abstracción consiste en que las normas del derecho escolar rigen sin hacer distinción entre las personas afectadas y sin tener en cuenta sus necesidades e intereses, seccionando con ello sus experiencias y deshaciendo así los contextos en que se desarrollan sus vidas. (Habermas, 1992, pp. 525-526) ${ }^{8}$

Habermas indica que esto termina representando una amenaza para la libertad pedagógica y la creatividad del profesor. En el caso colombiano,

8 Acá Habermas está citando a Frankenberg, G. (1978). Elemente einer Kritik und Theorie des Schulrechts, tesis doctoral, Munich, p. 217. 
esta potencial eliminación de la diversidad de opciones institucionales y pedagógicas la vemos manifestada en la práctica que suele verse en algunos colegios de solicitar a abogados el diseño de manuales de convivencia por encargo. Así, los manuales, en algunos casos, se convierten en códigos disciplinarios únicos que no tienen en cuenta las particularidades de los miembros de la comunidad educativa sobre la cual recaen (edad, representación étnica, género, etc.). El Estado colombiano reconociendo este hecho ha promovido mediante la ley de convivencia escolar retomar procesos pedagógicos y abandonar los procesos disciplinarios.

\section{Bobbio y la apuesta por la democracia social}

En su texto El futuro de la democracia, el filósofo del derecho Norberto Bobbio presenta una serie de reflexiones sobre las transformaciones contemporáneas de la democracia. Para Bobbio, "en el mundo la democracia no goza de óptima salud, y por lo demás tampoco en el pasado pudo disfrutar de ella, sin embargo, no está al borde de la muerte" (Bobbio, 1986, p. 7). Aunque, como el mismo Bobbio lo señala, los textos contenidos en su libro tienen una clara intención divulgativa, esto es, son textos que podrían ser catalogados como de "filosofía popular" (p. 11), lo cierto es que sus reflexiones presentan un elemento de gran relevancia para la teoría democrática en general y para nuestro tema en particular, ${ }^{9}$ y nos llevan a una valoración diferente del conflicto descrito en la introducción.

Según el iusfilósofo italiano, la transformación más relevante de la teoría y práctica democrática tiene que ver con la profundización y el desarrollo de los principios democráticos en los ámbitos sociales. Esto implica que las reglas democráticas deben llevarse a las esferas que no se consideraban hasta la fecha relacionadas con la política, como lo son, por ejemplo, la escuela y la fábrica. Esto es lo que Bobbio llamará "democracia social".

9 La democracia es uno de los temas a los que Bobbio regresa constantemente en su reflexión. Para profundizar en sus inquietudes sobre la democracia recomendamos la revisión de sus libros: Liberalismo y democracia (2000), De la razón de Estado al gobierno democrático (2014), El tiempo de los derechos (1991) y Democracia y secreto (2013). En ellos consolida sus temores frente al sistema democrático y a su vez toda su fe en que, aun con sus problemas, es el único que realmente puede transformar la realidad social de los ciudadanos. 
Ahora bien, antes de tematizar tal concepto, es necesario señalar que para Bobbio existen tres elementos básicos que caracterizan la democracia y que configuran una definición mínima de democracia. El primer elemento consiste en la existencia de un conjunto de reglas fundamentales que establecen quiénes están autorizados para tomar las decisiones que afectan a toda la sociedad, así como los procedimientos para elegir a esas personas y para tomar tales decisiones. El segundo elemento cualifica la naturaleza de la atribución realizada en el primer elemento. En efecto, según Bobbio, la democracia requiere que tal poder y derecho se debe otorgar a un número muy elevado de los integrantes de la colectividad. De una u otra forma toda democracia requiere que en las decisiones colectivas la participación sea considerablemente amplia. Finalmente, el tercer elemento consiste en la necesidad de que "aquellos que están llamados a decidir o a elegir a quienes deberán decidir, se planteen alternativas reales y estén en condiciones de seleccionar entre una u otra" (Bobbio, 1986, p. 15).

Las observaciones de Bobbio (1986) sobre la democracia social se presentan en el contexto de la discusión según la cual la única forma de revitalizar la democracia en las sociedades occidentales contemporáneas es la sustitución de la democracia representativa por la democracia directa (p. 32). Para el iusfilósofo italiano, no obstante,

[...] la democracia representativa y la democracia directa no son dos sistemas alternativos, en el sentido de que allí donde existe uno no puede existir el otro, sino que son dos sistemas que pueden integrarse recíprocamente. Se puede decir con una fórmula sintética que en un sistema de democracia integral las dos formas de democracia son necesarias, pero no son, consideradas en si mismas, suficientes. (Bobbio, 1986, pp. 40-41)

Por esto, Bobbio postula una posible alternativa, a saber, la democracia social. En sus palabras:

[...] es posible decir que si se puede hablar hoy de un proceso de democratización, éste consiste no tanto, como erróneamente se dice, en el paso de la democracia representativa a la democracia directa, como 
en el paso de la democracia política en sentido estricto a la democracia social, o sea, en la extensión del poder ascendente, que hasta ahora había ocupado casi exclusivamente el campo de la gran sociedad política [...] al campo de la sociedad civil en sus diversas articulaciones, desde la escuela hasta la fábrica: hablo de escuela y de fábrica para indicar simbólicamente los lugares donde se desarrolla la mayor parte de la vida de la mayoría de los miembros de una sociedad moderna [...]. (Bobbio, 1986, p. 42)

Una vez conquistada la democracia política nos damos cuenta de que la esfera política está comprendida a su vez en una esfera mucho más amplia que es la de la sociedad en su conjunto, y que no hay decisión política que no esté condicionada o incluso determinada por lo que sucede en la sociedad civil. Entonces, nos percatamos de que una cosa es la democratización del Estado, lo que sucedió generalmente con la institución de los parlamentos, y otra cosa es la democratización de la sociedad, por ello puede darse perfectamente un Estado democrático en una sociedad en la cual la mayor parte de sus instituciones, la familia, la escuela, la empresa y la administración de servicios no sean gobernadas democráticamente. De ahí la pregunta que caracteriza mejor que cualquier otra el momento actual que vive el desarrollo de la democracia en los países políticamente democráticos: ¿Es posible la sobrevivencia de un Estado democrático en una sociedad no democrática? Esta pregunta también puede ser formulada de la siguiente manera: la democracia política ha sido y es necesaria, con el objeto de que un pueblo no caiga bajo un régimen despótico pero, ¿es suficiente? (Bobbio, 1986, p. 43)

No parece posible que sobreviva la democracia si la sociedad se encuentra atravesada por prácticas autoritarias, sin embargo, esto precisamente demuestra que la democracia para el filósofo italiano no puede ni debe quedarse anclada a la democracia política, sino debe trascender en todos los escenarios sociales para que cumpla su cometido. La discusión ya no puede ser cómo lograr mayor participación ciudadana en las decisiones políticas (cuando ya se ha alcanzado la universalidad del voto, logro máximo democrático); para su futuro, la democracia debe implicar la participación del ciudadano en los espacios sociales en los que se encuentra. Como lo señala García Roca (1991), en su reflexión acerca de la propuesta de Bobbio: 
La democracia política es sólo una avanzadilla que tiene efectos multiplicadores en todos los ámbitos. Una vez implantada en la esfera política, posee un efecto expansivo hacia la esfera social, allí donde el individuo ejerce de padre y de hijo, de empresario y de trabajador, de médico y de enfermo, de enseñante y de estudiante, de administrador y de administrado, de jerarca y de creyente... Le es esencial al proceso ocupar nuevos espacios que quizá hasta ahora estaban dominados por organizaciones de tipo jerárquico y burocrático. (Bobbio, p. 175-176). No resulta insignificante desconcentrar el poder y ampliar los espacios y las redes de participación (p. 61)

Ese efecto expansivo debe afectar los problemas que traen consigo las jerarquías impuestas por las organizaciones sociales y las trabas procedimentales que surgen de la burocratización de las intermediaciones que implican la centralización del poder. De tal suerte que ese salto a la democracia social se reconoce como la posibilidad de perfeccionamiento de la democracia política, cuya problemática se recalca en que esta se queda corta frente a las necesidades de los ciudadanos.

En la propia extensión del término democracia señalado antes radica el problema que Bobbio pretende señalar: su discurso apunta a la necesidad de reconocer la exigencia de la ampliación de los espacios democráticos del plano donde los agentes sociales intervienen en calidad de ciudadanos (democracia política) a los otros planos donde intervienen debido a la diversidad de sus funciones y papeles específicos (democracia social). (Yturbe, 2007, p. 121)

Así, la noción de democracia social implica la promoción de la participación de los ciudadanos en las esferas de la sociedad en las que están vinculados, ya no como sujetos pasivos que reciben las decisiones tomadas jerárquicamente, sino como sujetos que actúan para orientar el rumbo de su sociedad. El ciudadano en la democracia social encuentra su lugar en la toma de decisiones en las esferas sociales que le son competentes y que lo definen como persona.

Ahora bien, sin lugar a dudas, la democracia social implica que el derecho se inmiscuya en los espacios sociales en los que las decisiones no son participativas. Así, se busca que los integrantes de todos los ámbitos 
sociales tengan realmente representación en las decisiones que los afectan, como sucedería, por ejemplo, si los estudiantes son representados por estudiantes en los órganos directivos de las escuelas o si los obreros son representados por obreros en las juntas directivas de las empresas.

Consideramos que la noción de Bobbio de democracia social puede servir para entender la discusión sobre los manuales de convivencia en las instituciones educativas en Colombia. En efecto, un elemento del conflicto descrito es la poca participación real de los estudiantes en la creación de las reglas que van a orientar la convivencia escolar, lo cual hace que la exigibilidad de su cumplimiento se centre en muchos casos en un argumento de autoridad ${ }^{10}$ en donde, "ante la impotencia de profesores y coordinadores para obtener determinados comportamientos de los estudiantes, necesitan colocar por delante la existencia de un documento que debe cumplirse taxativamente y unos procedimientos sancionatorios que deben aplicarse para conseguir la anhelada disciplina" (Aristizábal \& López, 2014, p. 62).

La Corte Constitucional colombiana ha entendido a los manuales de convivencia como "la expresión formalizada de los valores, ideas y deseos de la comunidad educativa (directivos, padres de familia, docentes, egresados y estudiantes) con respecto a su proyecto de formación escolar". (Corte Constitucional, Sentencia SU-641 de 1998). En este sentido, el proceso democrático respecto a los manuales supone una construcción colectiva, puesto que en él deben tener voz y voto estudiantes, profesores, directivos, administrativos, padres de familia e incluso egresados (Congreso de Colombia, Ley 1620 de 2013). De tal suerte que cada uno de los afectados por las reglas que se van a aplicar pueda implicarse en el proceso de creación participando en su construcción desde su rol específico.

Si bien los manuales se entienden también como contratos de adhesión a los que los participantes se adhieren al firmar unas condiciones mínimas bajo los valores de la comunidad educativa en la que se inscriben,

10 Esto referido a las reglas que sin contrariar la constitución podrían ser exigibles pero que tienen un bajo cumplimiento por ausencia de un acuerdo en su creación. Con relación a las reglas inconstitucionales que sancionan por ejemplo la orientación e identidad sexual protegidas por el ámbito del libre desarrollo de la personalidad no serían legítimas ni aún con la participación mayoritaria de los miembros de la comunidad educativa. 
este rasgo no niega la necesidad de transformación constante, puesto que los manuales también deben permitir la posibilidad de reevaluar las bases sobre las que se sustentan y propiciar una discusión permanente $\mathrm{y}$ vinculante.

De ahí que la democracia social de Bobbio implique un alto grado de constitucionalización y juridización de la vida cotidiana; constitucionalización que, como lo ha señalado Restrepo (2002), hace visible las grandes estructuras de opresión social existentes en la sociedad colombiana y, a la vez, "el lenguaje constitucional de las decisiones de la Corte tiende a propiciar debates sociales alrededor de temas que, seguramente, si no fuera por tal intervención, se demorarían muchos años más en poder ser discutidos públicamente; es el caso de las libertades sexuales, por citar sólo un ejemplo" (Aguirre \& Pabón, 2007). Solo desde esta reivindicación de los espacios participativos la democracia encuentra una nueva vitalidad.

\section{Conclusiones}

La descripción realizada por Habermas sobre los procesos de juridización como ejemplos de su tesis sobre la colonización del mundo de la vida tiene una gran fuerza explicativa de los malestares experimentados por los profesores y las directivas educativas; no obstante, debe ser contrastada con la realidad de una sociedad civil colombiana caracterizada por altas dosis de autoritarismo y exclusión. La colonización sistémica del mundo de la vida no parece necesariamente una situación negativa si, de una u otra forma, esa colonización obliga a un mundo de la vida autoritario y excluyente a abrirse a otras posibilidades. ${ }^{11}$ Es pertinente recordar como ejemplo de este intento de apertura las distintas normas y directrices que ha intentado desarrollar el Estado colombiano con la finalidad de promover la inclusión, respeto a los derechos humanos y aceptación a la diversidad, y que han sido atacadas por algunos sectores reivindicando una especie de derecho a discriminar, que entienden

11 Este doble proceso que de ida y vuelta entre la integración social del mundo de la vida y la integración sistémica ha sido reconocido por Habermas en sus reflexiones posteriores. Habermas, J. (2000). La constelación posnacional. España: Paidos. 
amparado en el libre desarrollo de la personalidad, o, incluso, en el derecho a la libertad religiosa. ${ }^{12}$

Es además innegable que las sociedades contemporáneas no se comprenden por fuera de las reglas jurídicas pues el derecho ha permeado en todas partes, incluso en la escuela. De ahí que suela hablarse de "sistema educativo" para referirse a todos los procesos que se desarrollan en la escuela. Lo cierto es que desde hace ya un buen tiempo la práctica educativa dejó de ser asunto solamente de los maestros y de las familias, y ha pasado a ser objeto de planeación y racionalización rigurosa por parte del Estado y de la sociedad (Vasco, Martínez \& Vasco, 2008, p. 112), sin que esto implique que todas las relaciones pedagógicas del sistema educativo deben estar juridizadas.

En este contexto, la propuesta de Bobbio permite entender la jurisprudencia constitucional sobre los manuales de convivencia y los derechos fundamentales de los estudiantes como una manifestación de la democracia social, esto es, como una forma de desarrollar los principios democráticos en espacios sociales no democráticos, a partir del fortalecimiento de la posibilidad de que los estudiantes se preparen activamente en el ejercicio democrático desde temprana edad. Esta necesidad de participación democrática en la construcción de reglamentos escolares se acercaría más al ideal de democracia social y al logro de la paz y la convivencia escolar, al permitir construir reglas que tengan mejores niveles de aceptación: "cuando un colectivo decide cuáles deben ser las normas que lo regulan, es necesario que sean reconocidas y asumidas por todos sus miembros, y la única forma de garantizar su reconocimiento es haciendo partícipes de su gestión (elaboración, aplicación, seguimiento, revisión) a las personas implicadas" (Caballero, 2010, p. 163 citado en Aristizábal \& López, 2014, p. 69).

12 Esta línea se hizo famosa en el Concepto del entonces Procurador General Alejandro Ordoñez con ocasión del estudio de la Ley 1482 de 2011, que penaliza las expresiones racistas y discriminatorias en contra de las minorías sociales. En su concepto, el jefe del Ministerio Público consideró que "las normas demandadas incluso podrían impedir que los padres de familia eduquen libremente a sus hijos". Este argumento fue empleado luego contra las cartillas que el Ministerio de Educación propuso como mecanismo pedagógico para formar en temas de género y Derechos Humanos y que fueron acusadas que promover una cierta "ideología de género" pese a que estaban asesoradas por expertos en la materia. 
De ahí que la aplicación del derecho en los ámbitos escolares no implique, necesariamente, una juridización negativa. Ya en la Teoría de la Acción Comunicativa, Habermas diferenciaba entre el derecho como medio y el derecho como institución jurídica. ${ }^{13} \mathrm{El}$ primero se refiere al derecho positivo sancionado por el Estado cuya validez y corrección quedan suficientemente legitimadas por el procedimiento a través del cual fue creado, este es el derecho con el que el Estado de Bienestar pretendía intervenir en la sociedad y direccionarla. En contraste, el derecho como institución se refiere a aquellas normas jurídicas cuya legitimación necesita presupuestos más profundos. En palabras del propio Habermas "típicos en este sentido son los fundamentos del derecho constitucional, los principios del derecho penal y del derecho de enjuiciamiento criminal y toda la legislación relativa a asuntos penales próximos a casos morales (como el asesinato, el aborto, la violación, etc.)" (Habermas, 1992, p. 516). Estas instituciones se reconocen porque cuando se cuestionan en la práctica cotidiana su validez no se resuelve con una simple apelación a su legalidad. Los principios de las instituciones jurídicas necesitan de "una justificación material, pues forman parte de los órdenes legítimos del mundo de la vida y, junto con las normas informales que rigen la acción, constituyen el trasfondo de la acción comunicativa" (Habermas, 1992, p. 517). Es por esto que en la vida cotidiana este tipo de derecho no aparece desligado de la moral. En palabras de Habermas: "las instituciones jurídicas tienen una función regulativa. Están insertas en un contexto político-cultural y social más amplio, guardan una relación de continuidad con las normas éticas, vienen a sancionar jurídicamente ámbitos de acción comunicativamente estructurados, proporcionan a los ámbitos de acción ya constituidos informalmente una fuerza vinculante respaldada por la sanción estatal" (Habermas, 1992, p. 517).

Pues bien, gran parte de los asuntos relacionados con la discusión de los manuales y los derechos fundamentales de los estudiantes tiene que ver con estas instituciones. Vale recordar que la Corte Constitucional ha reconocido que los manuales son "la expresión formalizada de los

13 Las reflexiones de Habermas sobre el derecho y sus posibilidades democráticas serán ampliadas posteriormente en su libro Facticidad y Validez. Por razones metodológicas, no incluimos esta perspectiva definitiva de Habermas. No obstante, sí nos atrevemos a señalar que van en un sentido muy similar, aunque mucho más elaborado y preciso. 
valores, ideas y deseos de la comunidad educativa" (Aguirre E Pabón, 2018, p. 30). Cuando una institución escolar, bajo el pretexto de alcanzar la disciplina, sanciona un determinado corte de cabello u orientación sexual recurriendo únicamente al principio de legalidad, desconoce la finalidad de los reglamentos escolares y la posibilidad de llegar a acuerdos razonables sobre cómo convivir con los otros. Un acuerdo razonable en una sociedad democrática no podría incluir reglas que promuevan la intolerancia o la discriminación.

Entonces, se podrían distinguir dos procesos de juridización: (i) aquellos que se conectan con instituciones jurídicas originadas en el mundo de la vida, y (ii) aquellos que implantan en ámbitos sociales las figuras del derecho positivo estatal funcionales para ámbitos de acción sistémicamente integrados (Habermas, 1992, p. 517). En este segundo caso, las regulaciones formales que ya existen se aplican en ámbitos en los que resultan extraños: piénsese por ejemplo en lo que puede pasar con el derecho al debido proceso en los manuales de convivencia si se pretende copiar las rigurosas garantías de un proceso penal.

La escuela ha sido y será valorada como un escenario propicio para formar en valores democráticos; es el espacio en el que se debe aprender a negociar, a construir acuerdos y a gestionar los conflictos. De ahí que, como lo señala el mismo Habermas, "El uso del derecho como medio debe sustituirse por procedimientos de regulación de los conflictos, que se ajusten a las estructuras de la acción orientada al entendimiento - por procesos de formación discursiva de la voluntad individual y colectiva y por procedimientos de negociación y decisión orientados hacia el consenso" (Habermas, 1992, p. 524). Esto implica institucionalizar, desde las particularidades de las escuelas, procedimientos consensuales de regulación de los conflictos que consideren a los implicados en el proceso pedagógico libres y capaces de defender sus intereses y de regular sus propios asuntos (Habermas, 1992, p. 527), lo cual permitiría pensar en la construcción de pactos de aula que reconozcan la diversidad de cada grupo y no en grandes regulaciones tipo código penal.

Ahora bien, también es necesario tener en cuenta la existencia de un conflicto que debe ser reconocido, nombrado y analizado, y que tiene raíces legítimas, lo que significa que ninguna parte del mismo debe ser menospreciada ni invisibilizada. Consideramos que esto es algo que se 
evita a partir de la discusión presentada entre la visión de Habermas sobre la juridización del mundo de la vida y la de Bobbio sobre la relevancia de la democracia social; en nuestro texto quisimos describir los dos extremos de tal conflicto en el contexto de una disputa entre, por una parte, la juridización de los procesos de enseñanza y aprendizaje en la escuela que se ha desarrollado en los últimos años y, por otra, la necesidad de profundizar el ideal democrático en las realidades escolares, en especial a partir de la defensa y garantía de los derechos fundamentales de los estudiantes. Aunque es innegable que en Colombia siempre ha existido a nivel social un equilibrio inestable entre la anomia y el autoritarismo, se pierden demasiados matices si el conflicto existente alrededor de los derechos fundamentales de los estudiantes y los manuales de convivencia de los colegios se reduce a una pugna instrumental de poderes entre, los estudiantes que no desean seguir las reglas y los profesores autoritarios incapaces de la formación democrática.

Las facultades de Educación, el Ministerio de Educación, y hasta FECODE deben esforzarse por continuar ahondando en el conocimiento de este conflicto, de forma tal que pueda ser entendido con más profundidad a la vez que se plantean soluciones concretas desde las visiones de los mismos participantes. Vale la pena notar que las breves observaciones realizadas por Habermas sobre la situación de la escuela alemana se fundamentan en la tesis doctoral de Günter Frankenberg titulada Elemente einer Kritik und Theorie des Schulrechts (1978). En este estudio, entre otras cosas, Frankerberg investiga los efectos de la juridización en el ámbito escolar desde la percepción de los profesores en relación con los mandatos jurídicos que deben cumplir. Según Frankenberg, citado por Habermas, en general se encuentran sentimientos de inseguridad en los profesores y reacciones que pueden describirse como un "sobrepasar o un quedarse por debajo del espacio de acción pedagógica, es decir, como una sobreacomodación a las normas vigentes o como una disfrazada desobediencia a ellas" (Habermas, 1992, p. 526).

Es cierto que el Ministerio de Educación ha realizado apuestas por cumplir sus funciones con la realización de talleres con los docentes y directivos; por tanto, no se puede concluir que este interés es inexistente. Pero estos esfuerzos han sido insuficientes. Vale la pena recordar que el pasado proceso de actualización de manuales de convivencia 
terminó suspendido por presiones de grupos sociales sin que a la fecha se hubiere reanudado.

Deben además ampliarse las investigaciones al respecto y conocer la voz de todos los actores del sistema nacional de convivencia escolar. En particular, debe estudiarse el papel de las familias y buscar integrar a este actor al proceso de formación.

Sin lugar a duda, también deben mejorarse las condiciones laborales de los maestros del sector oficial, y las instituciones privadas deben asumir una mayor responsabilidad social para que formarse en Derechos Humanos y ser formadores y mediadores no sea una carga laboral más de los maestros, sino una meta común de toda la institución. Si la infancia y la escuela son los primeros espacios en donde se vive la ciudadanía y la democracia, más allá del hogar, vale la pena seguir haciendo esfuerzos por construir escuelas que, si bien no estarán libres de conflictos, sí puedan contar con las suficientes herramientas pedagógicas para abordarlos en el marco de los valores democráticos.

\section{Referencias}

Acuña, A. (2018). La escuela territorio de paz, Una apuesta para el posacuerdo. Recuperado de https://www.magisterio.com.co/articulo/la-escuela-territoriode-paz-una-apuesta-para-el-posacuerdo

Aguirre, J. E Pabón, A. (2018). Justicia y derechos en la convivencia escolar. Análisis de la jurisprudencia de la Corte Constitucional colombiana sobre los derechos fundamentales de los estudiantes y los manuales de convivencia de las instituciones educativas. Bucaramanga: Universidad Industrial de Santander.

Aguirre, J. \& Pabón, A. (2007). El respeto a los derechos fundamentales en las instituciones educativas: una apuesta por la convivencia escolar. Revista de Derecho, (28), p. 243-281

Aristizábal, N. \& López, N. (2014). Resistencia vs. Norma: la convivencia escolar en cuestión. En, Entre luces y sombras: convivencia escolar y malestar docente (pp. 59-81). Popayán: Universidad del Cauca.

Bobbio, N. (1986). El futuro de la democracia. Ciudad de México: Fondo de Cultura Económica. 
Caracol Radio. (2016). Revisión de manuales de convivencia no es orientar preferencias sexuales. Recuperado de http://caracol.com.co/emisora/2016/08/06/ barranquilla/1470441250_219574.html

Chaux, E. (2012). Educación, convivencia y agresión escolar. Bogotá: Tauros Alfagura y Universidad de los Andes.

Congreso de la República de Colombia. (1991) Constitución Política de Colombia. Recuperado de http://www.corteconstitucional.gov.co/inicio/Constitucion\%20politica\%20de\%20Colombia.pdf

Congreso de la República de Colombia. (2013). Ley 1620. Recuperado de http:// www.imprenta.gov.co/gacetap/gaceta.mostrar_documento?p_tipo $=05 \& p_{-}$ numero $=062 \varepsilon p \_$consec $=48832$

Corte Constitucional de Colombia. (1998). Sentencia SU-641 de 1998 (M. P. Carlos Gaviria Díaz).

Corte Constitucional de Colombia. (23 de agosto de 2013). Sentencia T-562 de 2013 (M. P. Mauricio González Cuervo).

Corte Constitucional de Colombia. (23 de agosto de 2013). Sentencia T-565 de 2013 (M. P. Luis Ernesto Vargas Silva).

Corte Constitucional de Colombia. (13 de agosto de 2015). Sentencia T-478 de 2015 (M. P. Gloria Stella Ortiz Delgado).

De Zubiría Samper, S. (2002). Educación y Diversidad Cultural. Suma Cultural, (6), 23-45.

Fecode y Centro de Estudios e Investigaciones Docentes (CEID). (2016). Escuela, territorio de paz. Recuperado de http://fecode.edu.co/ceid/images/ documentos2017/Escuela\%20territorio\%20de\%20paz.pdf

García Roca, J. (1991). El desarrollo de los derechos sociales en un Estado de Bienestar. En J. Almarza (Coord.). Bienestar Social y Desarrollo de los Derechos Sociales. Salamanca, España: Editorial San Esteban.

Granados, P. (2014). La escuela como reflejo de las tensiones de la sociedad actual. En, Entre luces y sombras: convivencia escolar y malestar docente (pp. 43-56). Popayán: Universidad del Cauca, p. 43-56.

Habermas, J. (1992). Teoría de la acción comunicativa, II. Madrid, España: Santillana, S.A.

Habermas, J. (2000). La constelación posnacional. España: Paidos.

Osorio, M. \& Del Pilar, M. (2012). Análisis de los manuales de convivencia de las instituciones de educación media en Bogotá. Un estudio de caso. Revista RIIEP, 5(1), 79-92.

Restrepo, E. (2002). Reforma Constitucional y Progreso Social: La "Constitucionalización de la Vida Cotidiana". En Colombia. SELA (Seminario en 
Latinoamérica de Teoría Constitucional y Política) (pp. 1-13). Recuperado de https://digitalcommons.law.yale.edu/cgi/viewcontent.cgi?referer=https:// www.google.com/Ehttpsredir=1 Earticle=1013Econtext=yls_sela

Semana. (1993). Cinco en tutela. Recuperado de https://www.semana.com/ vida-moderna/articulo/cinco-tutela/20142-3

Yturbe, C. (2007). Pensar la democracia: Norberto Bobbio. México: Universidad Nacional Autónoma de México.

Vasco, C., Uribe, A., Martínez B., \& Vasco, E. (2008). Educación, pedagogía y didáctica: una perspectiva epistemológica. En Filosofía de la educación (pp. 99127). Madrid: Editorial Trotta, Consejo Superior de Investigaciones Científicas. 